\title{
Study of Dielectric Relaxation in $\mathrm{Zn}, \mathrm{Cd}$, and Hg, Ethanolamine Complexes
}

\author{
Adly H. Elsayed and A.M.Haffz \\ Physics Department, Faculty of Science, Alexandria University, \\ Alexandria, Egypt.
}

The dielectric constant $\varepsilon^{\prime}$ and dielectric loss $\varepsilon^{\prime \prime}$ for $\mathrm{Zn}(\mathrm{II}), \mathrm{Cd}(\mathrm{II})$ and $\mathrm{Hg}(\mathrm{II})$ ethanolamine complexes, which become semiconducting materials in their ligand structure, have been measured in the temperature (100-300K) and frequency $(1 \mathrm{kHz}-13 \mathrm{MHz})$. The temperature variation of $\varepsilon^{\prime}$ and $\varepsilon^{\prime \prime}$ does not have a peak within the frequency range of the investigations, unlike many semiconducting glasses. Howevere, the imaginary parts, $M$ ", of the dielectric modulus, $M^{*}$, have peaks indicating Deby-type dielectric relaxation behaviour with a distribution of relaxation times. The relaxation behaviour is thermally activated with activation energy of about $0.3 \mathrm{eV}$.

\section{Introduction:}

Amino alcohol complexes have received much interest because of their applications in different fields such as buffers, catalysts, inhibitors, ion exchangers, additives in building materials, electroplating and dyes [1-6]. Recently, some of these materials with Monoethanolamine (MEA), Diethanolamine (DEA) and Triethanolamine (TEA) as ligand have been prepared and show glassy semiconductor materials [7 \& 8]. Extensive studies on the structural chemistry, spectroscopic and thermal analysis of the aminoalcohol complexes were published [9-13]. The a.c electrical studies of the complexes reveal some structural details and add valuable complementary information relevant to electrical application of polymer materials. On the other hand, certain dielectric quantities or functions are employed more often than others depending on the particular field application. It is to be noted that different conduction mechanisms can exist in organometallic complexes. Some of them are well established such as electron hopping and polarization conduction. In the present paper, we report extensive studies of dielectric relaxation of the three octahedral $\mathrm{Zn}, \mathrm{Cd}$, and $\mathrm{Hg}$ (MEA) $)_{2}$ complexes. It has shown that the gradual change from $3 \mathrm{~d}$ to $5 \mathrm{~d}$ electron (i.e from $\mathrm{Zn}$ to $\mathrm{Hg}$ ) plays a major role in controlling their behaviour. 


\section{Experimental:}

Detailed method of preparation of these complexes and their analytical data have been discussed in reference [14]. The solid metal-amino alcohol complexes were prepared by mixing the required weight of the metal salt ( $\mathrm{Zn}$ $\mathrm{SO}_{4}, \mathrm{Cd} \mathrm{SO}_{4}$ and $\mathrm{Hg} \mathrm{Cl}_{2}$ ) dissolved in the least amount of water with the calculated amount of the ligand saturated with ethanol. The mixture was refluxed for about $5 \mathrm{~min}$. The complexes were precipitated and filtered, washed several time with a mixture of $\mathrm{EtOH}-\mathrm{H}_{2} \mathrm{O}$ solvent, then dried in vacuum desiccators over anhydrous $\mathrm{CaCl}_{2}$. The complexes were pressed into discs of $10 \mathrm{~mm}$ diameter and $1.0 \mathrm{~mm}$ thickness at a pressure of $0.9 \mathrm{G} \mathrm{Pa}$. Silver paste was painted on the major faces of each test piece as electrodes. The capacitance $\mathrm{C}(\omega)$, the phase angle $\varphi$, the loss factor $\tan \delta$, and the impedance $Z(\omega)$ were measured simultaneously at frequencies from $1 \mathrm{kHz}$ to $13 \mathrm{MHz}$ in the temperature range 100-300 K using LCR meter (4275A). The dielectric constant $\varepsilon^{\prime}$, the dielectric loss $\varepsilon^{\prime \prime}$ and the dielectric modulus $\mathrm{M}^{*}$ were calculated as discussed below. Carbon, Hydrogen, Nitrogen and sulphate contents were determined at the microanalytical center, Faculty of Science, Cairo University, EGYPT. The $\mathrm{Zn}, \mathrm{Cd}$, and $\mathrm{Hg}$ contents were done complexometrically [15]. All the analytical data as well as the dielectric relaxation data are collected in Table(1). Structural chemistry for the prepared octahedral complexes through this manuscript are summarized in Fig.(1).

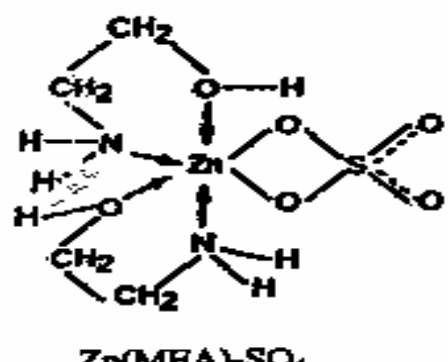

Zn(MEA) SO

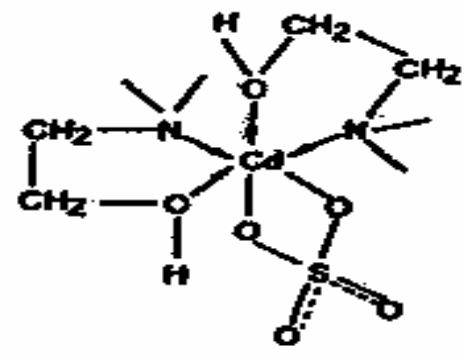

CdMEA)SO4<smiles>CO[NH2+]N(C)OC</smiles>

$\mathrm{Hg}(\mathrm{MEA})_{2} \mathrm{Cl}_{7}$

Fig.(1): Structural chemistry for $\mathrm{Zn}(\mathrm{MEA})_{2} \mathrm{SO}_{4}, \mathrm{Cd}(\mathrm{MEA})_{2} \mathrm{SO}_{4}$ and $\mathrm{Hg}(\mathrm{MEA})_{2} \mathrm{Cl}_{2}$ complexes. 


\section{Results and Discussions:}

Ac response of a material can be expressed as complex impedance $Z^{*}$, complex dielectric constant $\varepsilon^{*}$ and complex dielectric modulus $\mathrm{M}^{*}$. These functions are given as;

$$
\begin{aligned}
& \varepsilon^{*}=\varepsilon^{\prime}-\mathrm{i} \varepsilon^{\prime \prime} \\
& Z^{*}=Z^{\prime}-\mathrm{i} Z^{\prime \prime} \\
& M^{*}=M^{\prime}+\mathrm{i} M^{\prime}
\end{aligned}
$$

where $\varepsilon^{\prime \prime} / \varepsilon^{\prime}=\tan \delta=\mathrm{M}^{\prime \prime} / \mathrm{M}^{\prime}=\mathrm{Z}^{\prime} \mathrm{Z}^{\prime} \mathrm{Z}^{\prime}$ and $\tan \delta$ is the loss factor, which gives directly the phase difference due to the absorption of energy.

The complex dielectric constant $\varepsilon^{*}(\omega)$ is related to the measured capacitance $\mathrm{C}(\omega)$ as ; $\varepsilon(\omega)=\mathrm{C}(\omega) \mathrm{d} / \varepsilon_{0} \mathrm{~A}$, where $\mathrm{A}$, $\mathrm{d}$ are the cross-section area and thickness of the sample respectively and $\varepsilon_{\mathrm{o}}$ is the permittivity of the free space. The real component $\varepsilon^{\prime}$ and the imaginary component $\varepsilon^{\prime \prime}$ of the complex dielectric constant $\varepsilon^{*}(\omega)$ are related to the measured impedance $\mathrm{Z}$ and the phase angle $\varphi$ as follows [16],

$$
\begin{aligned}
& \varepsilon^{\prime}=Z^{\prime} / \omega|Z|^{2} C_{o} \\
& \varepsilon^{\prime \prime}=Z / \omega|Z|^{2} C_{o}
\end{aligned}
$$

where $Z^{\prime}=|Z| \sin \varphi, Z^{\prime \prime}=|Z| \cos \varphi ; C_{0}=\varepsilon_{0} A / d$ is the air capacity and $\omega$ is the angular frequency $(\omega=2 \pi \mathrm{f})$. Hill and Jonscher $[17,18]$ describe the complex permittivity as,

$$
\varepsilon(\omega)=\varepsilon^{\prime}-\mathrm{i} \varepsilon^{\prime \prime}-\mathrm{i}\left(\sigma_{\mathrm{dc}} / \omega\right)+\varepsilon(\infty)
$$

where $\sigma_{\mathrm{dc}}$ is the zero frequency conductivity and $\varepsilon(\infty)$ is the limiting high frequency permittivity.

\subsection{Variation of $\varepsilon$ with temperature and frequency:}

Figure (2), shows the temperature dependence of the real part of the dielectric constant, $\varepsilon$, at different frequencies, for the three samples. The inset of this figure represents the variation of $\varepsilon^{\prime}$ with frequencies. No peak in $\varepsilon^{\prime}$ as a function of temperature is observed (it should be noted that the solid lines in Fig. 2 and other figures are guides for the eye). $\varepsilon$ ' varies very slowly with temperature to a temperature $T_{0}$, where $T_{0}$ is a function of composition of the samples. It was found that $T_{0}$ is approximately equal to half of the Debye temperature $\theta_{\mathrm{D}}$ of the respective samples (see table 1). The values of $\theta_{\mathrm{D}}$ are deduced from the dc conductivity data [8]. Above $T_{0}$, the values of $\varepsilon^{\prime}$ for all 
samples increase with increase of temperature and decrease with increase of frequency. Such behaviour indicates a Debye -type dielectric relaxation process with relaxation frequency $F_{r},\left(F_{r}=F_{o} \exp \left(-\Delta / k_{B} T\right)=1 / 2 \pi \tau, \tau\right.$ being the relaxation time and $\mathrm{F}_{\mathrm{o}}$ is the Debye phonon frequency, which may be related to $\mathrm{T}_{\mathrm{o}}, \mathrm{k}_{\mathrm{B}}$ is the Boltzmann's constant and $\Delta$ is the activation energy for conduction). This relaxation process can be more resolved from the calculation of dielectric modulus, $\mathrm{M}^{*}$, as discussed below. The observed values of $\varepsilon^{\prime}$ for $\mathrm{Zn}(\mathrm{MEA})_{2} \mathrm{SO}_{4}$ sample is much higher than other samples, which support the previous results of higher conductivity data than $\mathrm{Cd}$ or $\mathrm{Hg}$-complexes [8]. The frequency dependence of $\varepsilon^{\prime}$ for the three samples decrease with increase of frequency. It should be noted that no maxima in $\varepsilon^{\prime}$ as a function of frequency is observed. The decay rate of $\varepsilon^{\prime}$ for $\mathrm{Zn}$-complex is larger than $\mathrm{Cd}$ and $\mathrm{Hg}$ complexes Fig. (2a).

Table (1): Analytical data for the prepared octahedral complexes

\begin{tabular}{|c|c|c|c|c|c|c|c|c|c|}
\hline \multirow{2}{*}{ Complex } & \multirow{2}{*}{$\begin{array}{l}\text { Melting } \\
\text { Point } \\
\text { (K) }\end{array}$} & \multicolumn{4}{|c|}{ Weight (\%) } & \multirow{2}{*}{$\begin{array}{c}\mathrm{F}_{\mathrm{o}} \\
(\mathrm{Hz})\end{array}$} & \multirow{2}{*}{$\begin{array}{c}\Delta \\
(\mathrm{eV})\end{array}$} & \multirow{2}{*}{$\begin{array}{c}\mathrm{T}_{\mathrm{o}} \\
(\mathrm{K})\end{array}$} & \multirow{2}{*}{$\begin{array}{c}\theta_{\mathrm{D}} \\
(\mathrm{K})\end{array}$} \\
\hline & & Metal & $\mathrm{SO}_{4}$ & $\mathrm{Cl}_{2}$ & Ligand & & & & \\
\hline $\mathrm{Zn}(\mathrm{MEA})_{2} \mathrm{SO}_{4}$ & $>573$ & 23 & 33.8 & ---- & 43.2 & $6.1 \times 10^{11}$ & 0.28 & 240 & 510 \\
\hline $\mathrm{Cd}(\mathrm{MEA})_{2} \mathrm{SO}_{4}$ & $>538$ & 34.3 & 29 & ---- & 36.7 & $3.93 \times 10^{10}$ & 0.32 & 210 & 450 \\
\hline $\mathrm{Hg}(\mathrm{MEA})_{2} \mathrm{Cl}_{2}$ & 536 & 50.9 & ---- & 18.1 & 31 & $1.64 \times 10^{11}$ & 0.37 & 190 & 400 \\
\hline
\end{tabular}

\subsection{Temperature and frequency dependence of $\varepsilon "$ :}

Figure (3), shows the temperature dependence of dielectric loss, $\varepsilon^{\prime \prime}$, at different frequencies, which is similar to the behaviour of $\varepsilon^{\prime}$. The frequency variation of $\varepsilon^{\prime \prime}$ at different temperature are shown in the inset of Fig.(3). For many semiconducting glasses, the dielectric relaxation time can be deduced from the observed peak when $\varepsilon$ 'and $\varepsilon$ "'are plotted as function of frequency [19]. As can be seen from Figures 2 and 3, $\varepsilon^{\prime}$ and $\varepsilon^{\prime \prime}$ for all samples do not have maxima when plotted as a function of temperature or frequency within the temperature range $(100 \mathrm{~K}-300 \mathrm{~K})$ and frequency range $(1 \mathrm{kHz}-13 \mathrm{MHz})$ of our investigations.

The well-known method of displaying Debye type relaxation is by drawing a Cole-Cole plot. Cole and Cole [20] suggested that $\varepsilon^{\prime}$ as a function of $\varepsilon^{\prime \prime}$ gives important information about the distribution of relaxation times. 

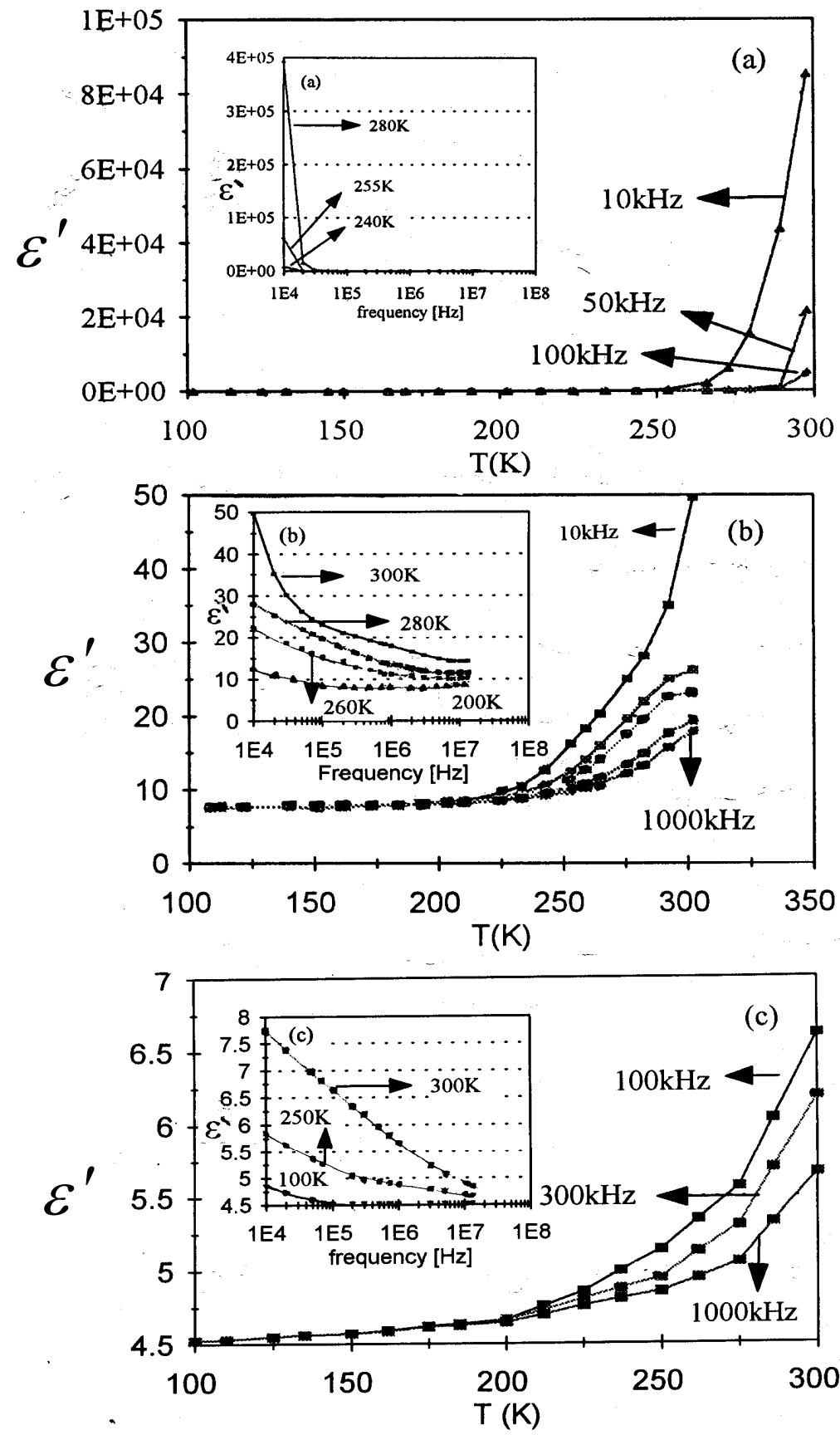

Fig.(2): Temperature dependence of dielectric constant $\varepsilon^{\prime}$ at different frequencies for:

a) $\mathrm{Zn}(\mathrm{MEA})_{2} \mathrm{SO}_{4}$, b) $\mathrm{Cd}(\mathrm{MEA})_{2} \mathrm{SO}_{4}$ and

c) $\mathrm{Hg}(\mathrm{MEA})_{2} \mathrm{Cl}_{2}$. The insets represents the variation of $\varepsilon^{\prime}$ with frequency at 
different temperatures.
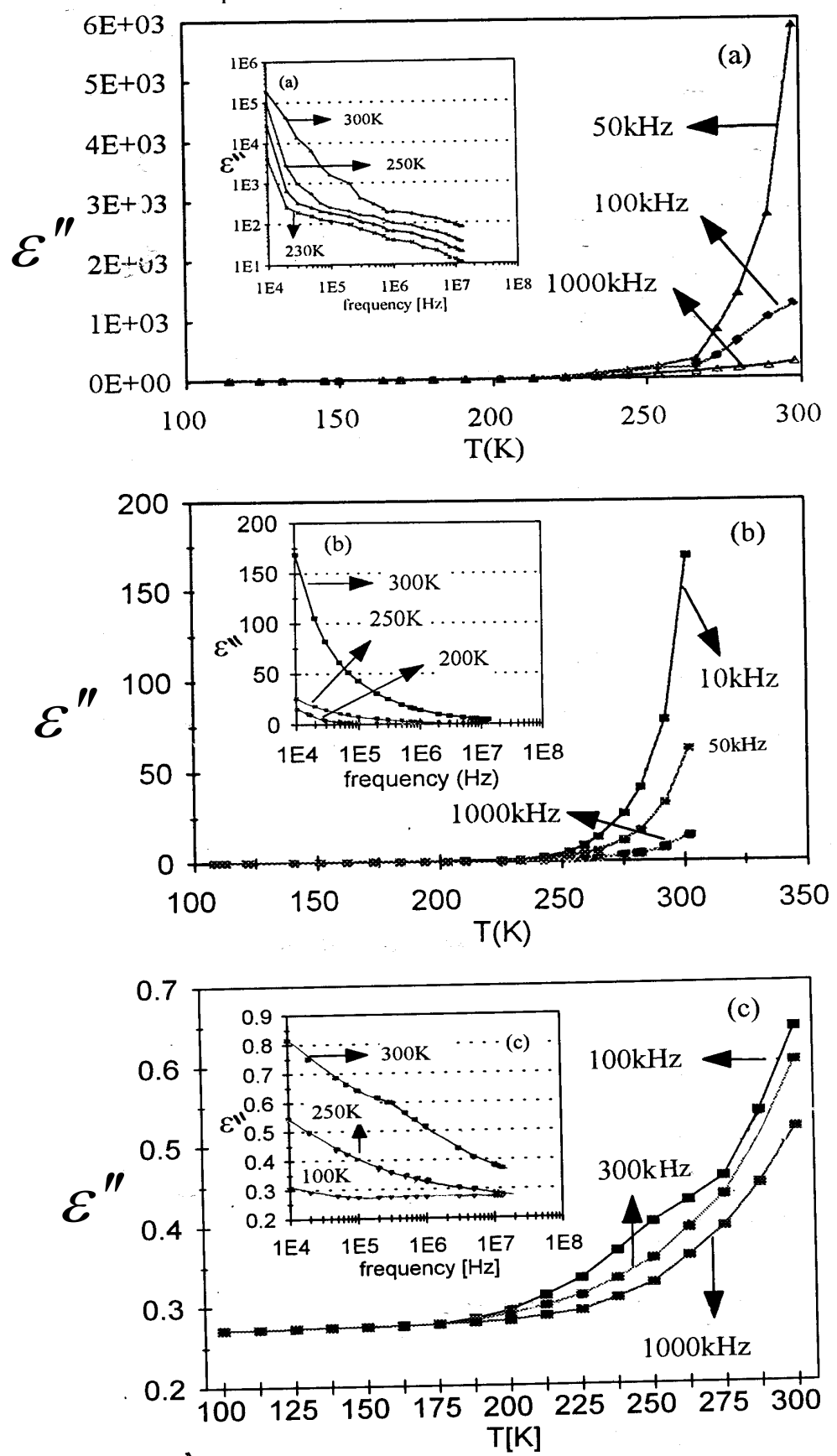

Fig.(3): Temperature dependence of dielectric loss $\varepsilon$ " at different frequencies for:

a) $\mathrm{Zn}(\mathrm{MEA})_{2} \mathrm{SO}_{4}$, b) $\mathrm{Cd}(\mathrm{MEA})_{2} \mathrm{SO}_{4}$ and

c) $\mathrm{Hg}(\mathrm{MEA})_{2} \mathrm{Cl}_{2}$. The insets represents the variation of $\varepsilon$ " with frequency at 
different temperatures.

The slope of the arc at $\varepsilon^{\prime \prime}=0$ is a measure of the extent of distribution of relaxation times. According to Cole and Cole, the complex dielectric is given by $\varepsilon^{*}=\varepsilon_{\infty}+\left(\varepsilon_{\mathrm{s}}-\varepsilon_{\infty}\right) /\left[1+(i \omega \tau)^{1-\beta}\right]$, where $\tau$ is the mean relaxation time,$\beta$ is an empirical parameter lying between 0 and 1 , and $\varepsilon_{\mathrm{s}}$ and $\varepsilon_{\infty}$ are the static and high frequency dielectric constants respectively. The slope of the Cole - Cole plot at $\varepsilon^{\prime \prime}=0$ gives the value of $(1-\beta) \pi / 2$. For $\beta=0$, it leads to a single relaxation time, $\beta=1$ corresponds to an infinite distribution of relaxation times. We have plotted $\varepsilon^{\prime \prime}$ versus $\varepsilon^{\prime}$ at different temperatures for all samples, but the data do not fit a semi-circular curve. According to Grant [21], the large value of high frequency capacitance or conductivity of the sample is responsible for such behaviour. In Fig.(4), we present the Cole-Cole plot for the three complexes at different temperature. From this figure, it is evident that $\beta$ for the three samples is greater than zero and less than 1. From this deduction we first suggest that these complexes have a distribution of relaxation times. It is difficult to use this conventional method of estimating the relaxation frequency and the magnitude of the dispersion. Therefore, another approaches has been adopted. The relaxation process can be more clearly resolved from the calculation of dielectric modulus $M^{*}$. Following Macedo et al [22], the real and the imaginary parts of dielectric modulus are related to $\varepsilon^{\prime}$ and $\varepsilon^{\prime \prime}$ as,

$$
\begin{aligned}
& M^{\prime}=\varepsilon^{\prime} /\left(\varepsilon^{\prime 2}+\varepsilon^{\prime \prime 2}\right) \\
& M^{\prime \prime}=\varepsilon^{\prime \prime} /\left(\varepsilon^{\prime 2}+\varepsilon^{\prime \prime 2}\right)
\end{aligned}
$$

The dielectric modulus, $\mathrm{M}^{*}$, provides information particularly when the $\mathrm{dc}$ conductivity is large compared with the ac conductivity.

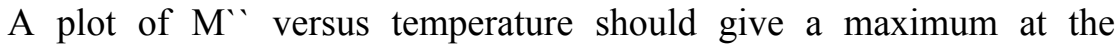
temperature for which the dielectric relaxation frequency is equal to the measuring frequency, (as will be shown down). We have plotted $M$ as a function of temperature for the complexes at different frequencies (Fig.5). From this figure, we observed that, at lower temperature, $M^{\prime}$ tends to a constant value for all frequencies. This dependence indicates that the dielectric constant of the samples is thermally activated. The imaginary part, $\mathrm{M}^{\prime \prime}$, was calculated and plotted as a function of temperature at different frequencies. An example is shown in Fig.(6). For $\mathrm{Zn}(\mathrm{MEA})_{2} \mathrm{SO}_{4}$ sample. The data in Fig.(6). Show maxima which shift to higher temperature for higher frequencies. Similar dependence of

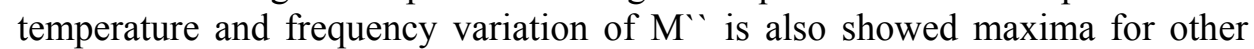
samples. The value of the temperature at the position of the maximum in (M“T) plots corresponds to the temperature at which the measuring frequency is equal to the relaxation frequency $\mathrm{F}_{\mathrm{r}}$. 

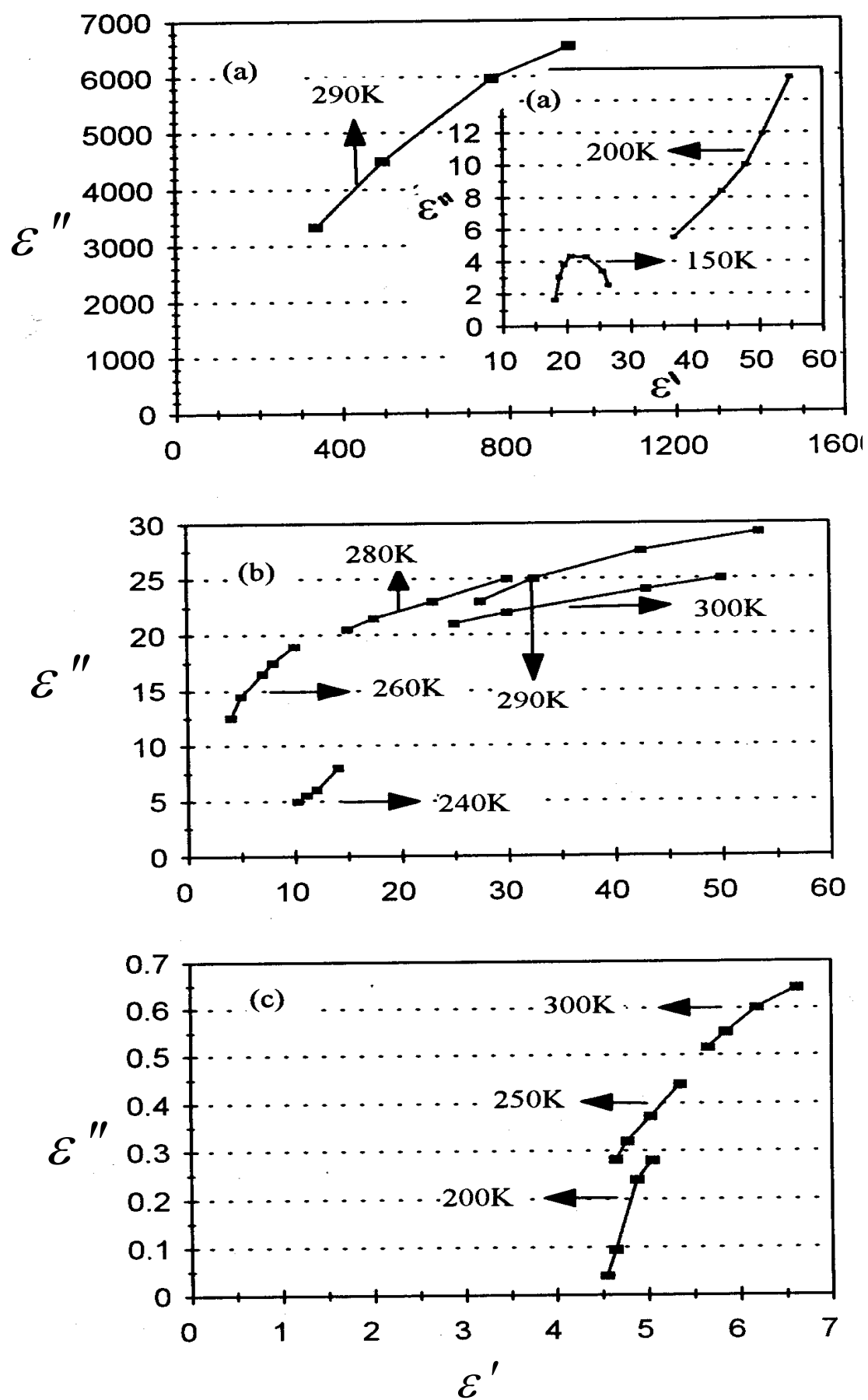

Fig.(4): Cole-Cole plots at different temperatures for : a) $\mathrm{Zn}(\mathrm{MEA})_{2} \mathrm{SO}_{4}$, b) $\mathrm{Cd}(\mathrm{MEA})_{2} \mathrm{SO}_{4}$ and c) $\mathrm{Hg}(\mathrm{MEA})_{2} \mathrm{Cl}_{2}$ complexes. 

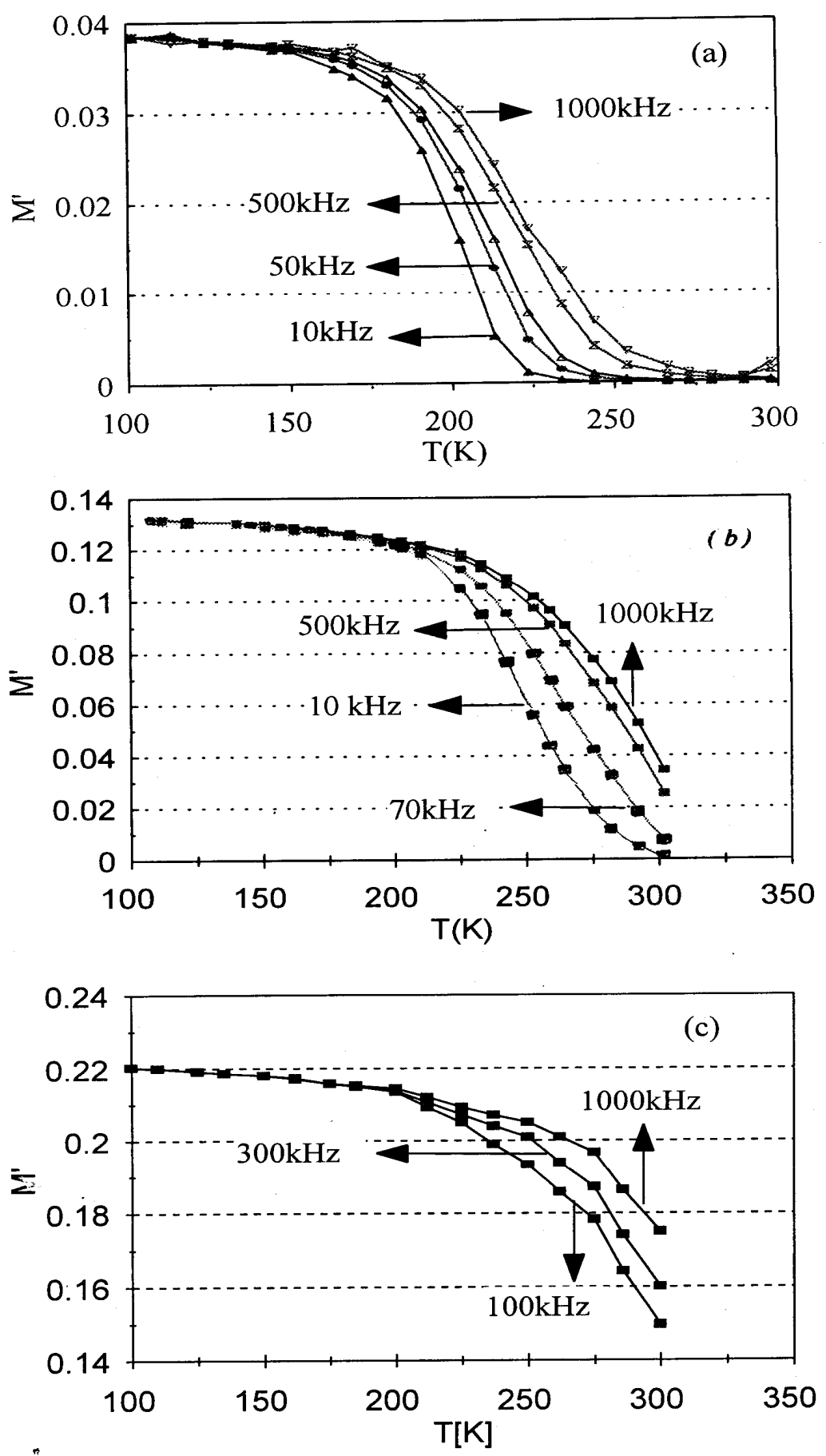

Fig.(5): Temperature dependence of dielectric modulus $\mathrm{M}^{`}$ at different frequencies for a) $\mathrm{Zn}(\mathrm{MEA})_{2} \mathrm{SO}_{4}$, b) $\mathrm{Cd}(\mathrm{MEA})_{2} \mathrm{SO}_{4}$ and c) $\mathrm{Hg}(\mathrm{MEA})_{2} \mathrm{SO}_{4}$ complexes. 


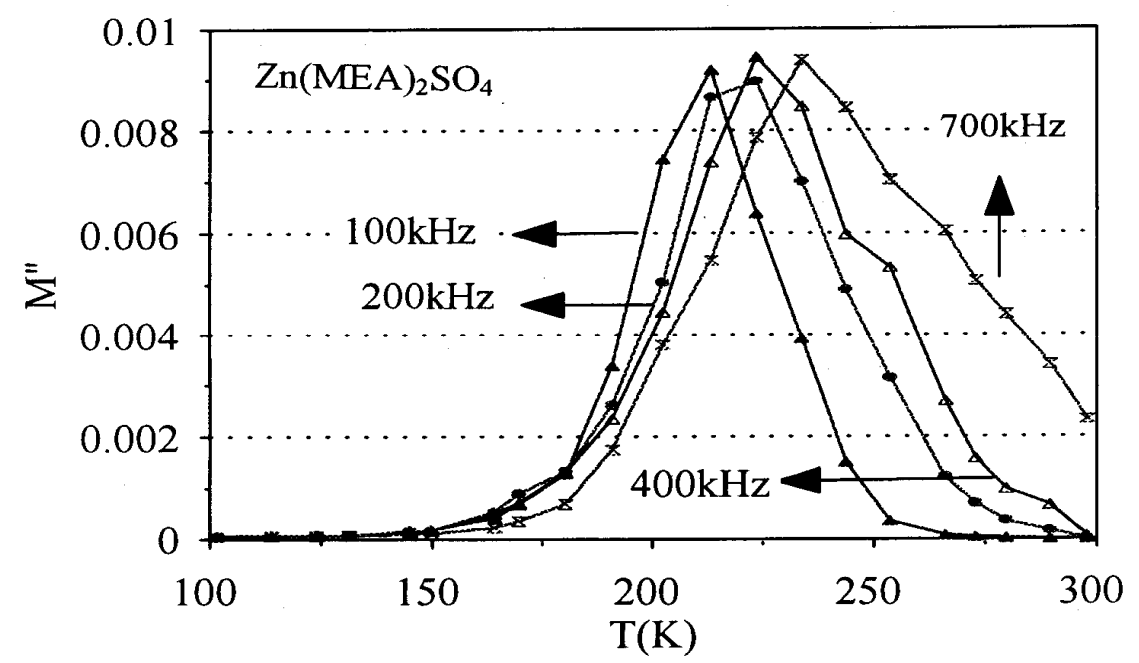

Fig.(6): Temperature dependence of imaginary part $\mathrm{M}^{\text {" }}$ at different frequencies for : $\mathrm{Zn}(\mathrm{MEA})_{2} \mathrm{SO}_{4}$ complex.

The observed peaks in (M"-T) plots indicates Debye-type relaxation behaviour [23]. Moreover, the imaginary part of dielectric modulus $\mathrm{M}^{\text {" }}$ are plotted in Fig.(7). as a function of frequency at different temperature. The relaxation time is defined as the inverse of angular frequency at the maximum of the $\mathrm{M}^{\prime}(\omega \tau=1)$. It has proposed $[24,25]$ that, if full width at half maximum is equal to 1.14 decade, then the peak is said to be an ideal Debye peak (i.e having single relaxation time) and if it is more than 1.14 decades, the relaxation times for different processes are comparable. Fig.(7). shows the spectroscopic plot of $\mathrm{M}^{\text {" vs }} \log \mathrm{F}$ for $\mathrm{Zn}(\mathrm{MEA})_{2} \mathrm{SO}_{4}$ complex at different temperatures. It has observed that full width at half maxima is in the range of 1.9 to 2.6 in the temperature region $300 \mathrm{~K}-210 \mathrm{~K}$, which is larger than an ideal Debye peak. This indicates that there is a distribution of relaxation times or/and there is more than one relaxation process involved. At temperature less than $210 \mathrm{~K}$, the observed peaks has width at half maxima much less than 1.14, involves one relaxation behaviour. The separate peaks in Fig.(7). corresponding to orientational polarization which involves short range movement of the electronic charge carriers may occur beyond the frequency range of measurements [26]. 


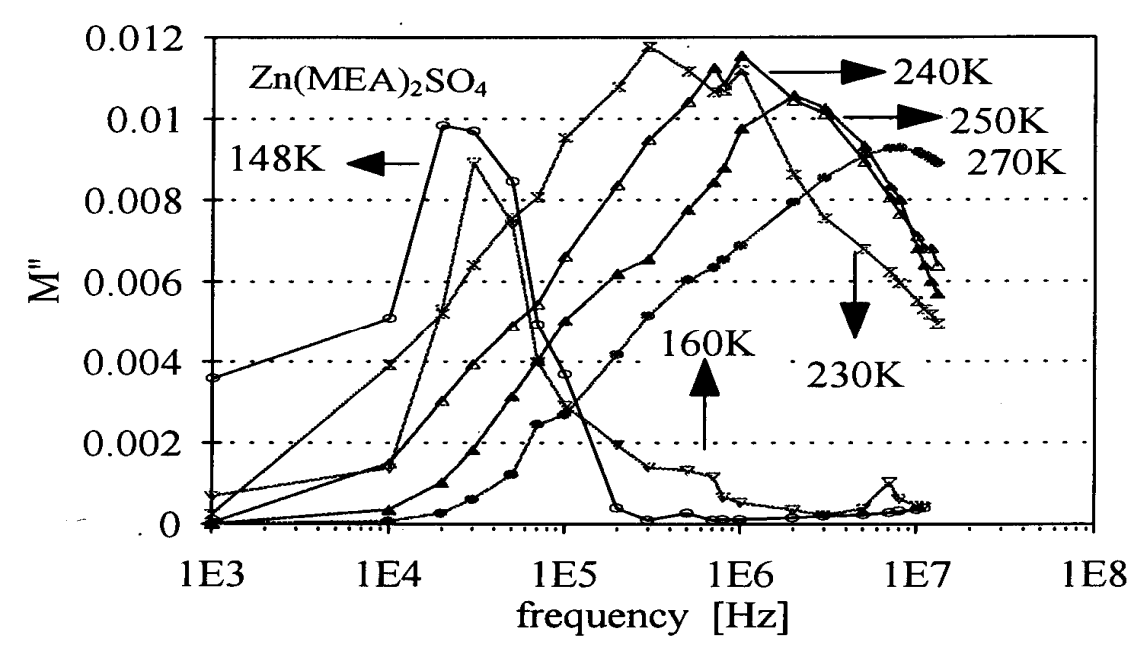

Fig.(7): $\mathrm{M}$ "versus $\mathrm{F}$ in $\log -\log$ scale at different temperatures for $\mathrm{Zn}(\mathrm{MEA})_{2} \mathrm{SO}_{4}$.

In-order to confirm the recorded values of relaxation rate $F_{r}$ from the maxima in (M"-T) and (M"-F) plots, a double-logarithmic plots of permitivity $\left(\varepsilon^{\prime}\right.$ and $\left.\varepsilon^{\prime \prime}\right)$ as a function of frequency are constructed for the investigated samples. An example is shown in Fig.(8). It can be seen that the imaginary component $\varepsilon$ " shows a power law behaviour $\varepsilon$ " $\alpha\left(F / F_{r}\right)^{-n}$ as observed in many transition metal glasses [27]. Where $\mathrm{F}_{\mathrm{r}}$ has a position near the intersection point between $\varepsilon^{\prime}$ and $\varepsilon^{\prime \prime}$ and $\mathrm{n}$ is the power exponent depends on temperature and frequency region. It was found from Fig.(8) that $F_{r}$ is approximately equal to the values obtained from maxima in both (M"- T) and (M"-F) plots. Also, the lower frequency region in Fig.(8)., $\varepsilon^{\prime \prime}$ are increased with a higher rate. In this case, there is no contribution from dc conductivity term in Eqn. (3), as explained by Hill and Jonscher [17]. The temperature dependence of the observed relaxation rate $\mathrm{F}_{\mathrm{r}}$ (Figs. $(6-8)$ ) for the $\mathrm{Zn}-{ }_{\text {, }} \mathrm{Cd}-$ and $\mathrm{Hg}-$ complexes are given in the form of Arrhenius plots in Fig.(9). From this Figure there is an evidence for activated processes with activation energy of about $0.3 \mathrm{eV}$, which is approximately equal to the values deduced from dc conductivity [8]. For $\mathrm{Zn}(\mathrm{MEA})_{2} \mathrm{SO}_{4}$ sample, Fig.(9) shows a distribution of relaxation times at temperature higher than $210 \mathrm{~K}$ with activation energy $0.28 \mathrm{eV}$ and one relaxation behaviour at temperature less than $210 \mathrm{~K}$ with activation energy equal to $0.09 \mathrm{eV}$. This lower value of activation energy may be due to the activation from the donor level to the conduction band i.e. extrinsic behaviour. It can be seen from Fig.(9) that, $\mathrm{Cd}-$ and $\mathrm{Hg}-$-complexes needs measurements at frequencies less than $1 \mathrm{kHz}$ in-order to observe relaxation behaviuor at temperature less than $200 \mathrm{~K}$. 

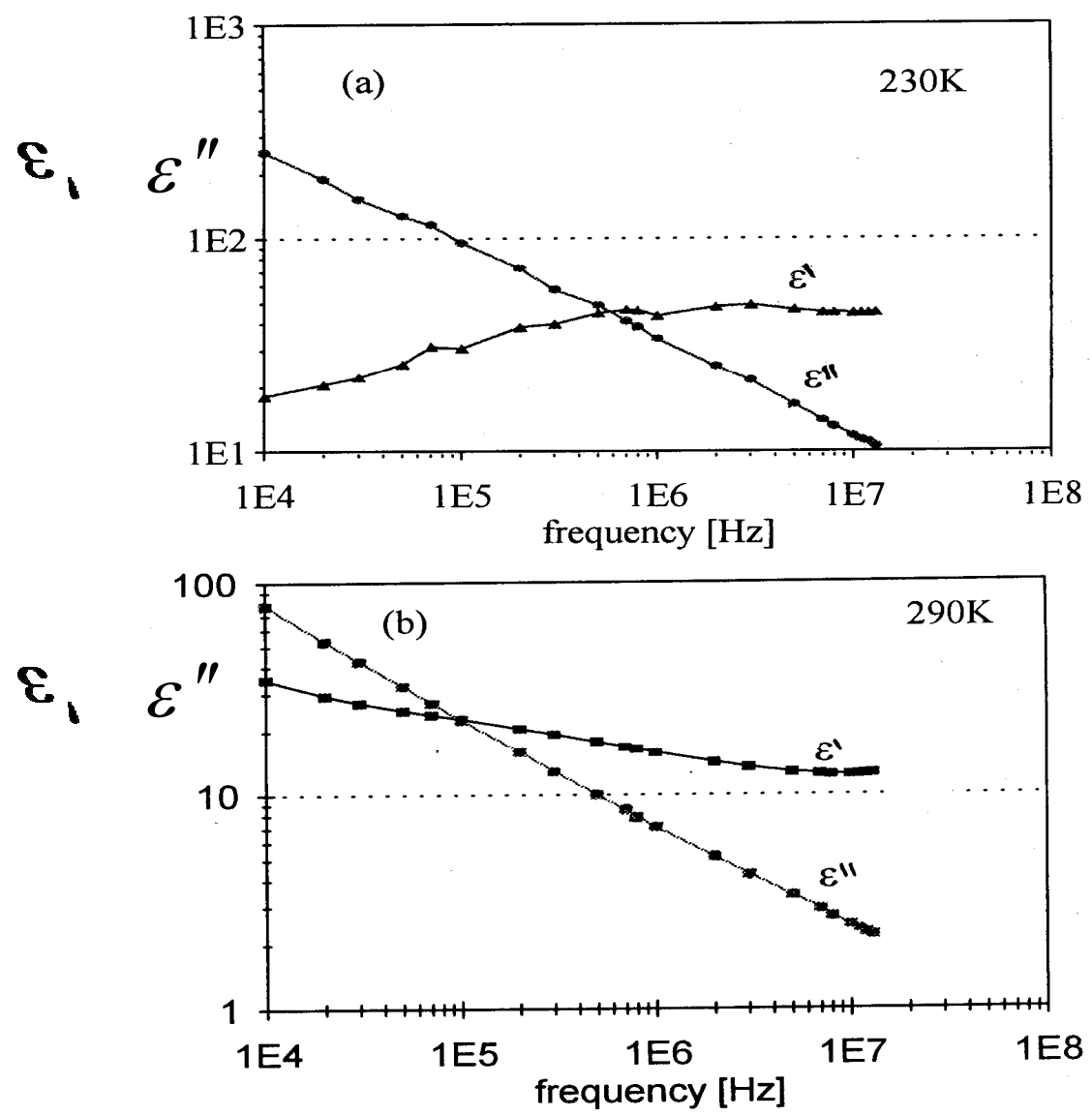

Fig.(8): $\log -\log$ plot of the permittivity $\left(\varepsilon^{\prime}, \varepsilon^{\prime \prime}\right)$ as a function of frequency for a) $\mathrm{Zn}(\mathrm{MEA})_{2} \mathrm{SO}_{4}$ and b) $\mathrm{Cd}(\mathrm{MEA})_{2} \mathrm{SO}_{4}$.

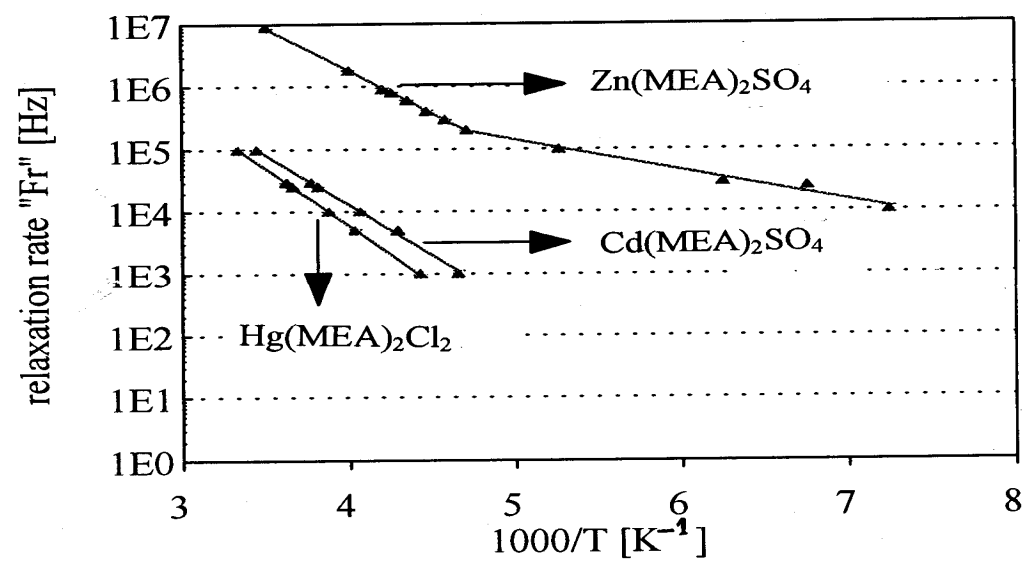

Fig.(9): The temperature dependence of the relaxation rate $\mathrm{F}_{\mathrm{r}}$ in $\mathrm{Zn}(\mathrm{MEA})_{2} \mathrm{SO}_{4}, \mathrm{Cd}(\mathrm{MEA})_{2} \mathrm{SO}_{4}$ and $\mathrm{Hg}(\mathrm{MEA})_{2} \mathrm{Cl}_{2}$ complexes in the form of Arrhenius plot (equation 5). 


\section{Conclusion:}

From Cole-Cole plots dielectric measurements seems to be Debye type with distribution of relaxation time. Temperature dependence of dielectric constant shows that $\varepsilon^{\prime}$ increased with a higher rate above certain temperature which indicates dipole polarization mechanism. At low temperature, the real part of dielectric modulus $M^{\prime}$ is constant over the frequency range $1 \mathrm{kHz}$ $13 \mathrm{MHz}$ indicates that the dielectric constant is thermally activated process. A separate peaks are observed in the temperature and frequency dependent of $\mathrm{M}^{\text {" }}$ with a half width greater than 1.14 in the temperature range $210 \mathrm{~K}$ to $300 \mathrm{~K}$, indicates again a distribution of relaxation time while at $\mathrm{T}<210 \mathrm{~K}$, the observed peaks has a half width less than 1.14 indicates single relaxation behaviour. The separate peaks in $\mathrm{M}^{\text {” }}$ vs $\log \mathrm{F}$ reveals the presence of orientational polarization. This is caused due to hopping of charge carriers among defect complexes within the bulk. The temperature dependence of the relaxation rate $F_{r}$ (Fig.9.) shows two relaxation conduction mechanisms in $\mathrm{Zn}(\mathrm{MEA}) 2 \mathrm{SO} 4$ complex with activation energy $0.28 \mathrm{eV}$ at temperature higher than $210 \mathrm{~K}$ which is due to thermal activated hopping of electronic charge carriers. Below $210 \mathrm{~K}$ the activation energy becomes $0.09 \mathrm{eV}$. The present of oxygen in octahedral structure may occur a vacancies, these vacancies may act as a donor, which is responsible for low activation energy at low temperatures. The values of activation energy deduced from dielectric relaxation are approximately equal to that obtained from dc conductivity measurements. Both activation energy and the characteristic phonon frequency $F_{o}$ are listed in Table(1).

Ac conductivity measurements for these complexes will be published soon in a separate article.

\section{Acknowledgments:}

Authors are grateful to prof. M.S. Masoud, Chemistry department, Faculty of Science, Alexandria University for sample preparation. A.M. Haffz, thanks the Institute of Physics, A.Mickiewicz University, Poznan, Poland for hospitality during his stay, and for allowing the use of LRC meter.

\section{References:}

1. M.Aloisi, Ann. Univ. Ferrera 2, 101 (1949).

2. I.A.Salem and Int. J. Chem. Kinet 26, 341 (1994).

3. T.K.Ross and C. Pearson, Corrosion Science 4, 449 (1964).

4. V.S. Klement, Neft. Khoz. 45, 19 (1967). 
5. K.S.Tomio Kudo, N. Asaoka, Jpn. Kokai Tokkyo Koho Jp 04,314,871(cl.C23C18/44), 06 Nov. (1992), Appl. 91/106, 572, 12 Apr. (1991); 6 pp, C.A. 118, 650675 (1993).

6. T.Bechtold, E. Burtgeher, A.Amann, O.Bobleter, J.Chem. Soc. Faraday Trans. 89, 2451 (1993).

7. M.S.Masoud, A.M.Haffz, A.Sh. Ramadan and A.Ali, J. Serbi, Chem. Soc. 67, 833 (2002).

8. M.S.Masoud, S. Mohga, Tawfik and M.E. El-Shabasy, El-Minia Science Bulletin (EGYPT), 6(2002)67.

9. M.S.Masoud and T.M.Salem, J. Electro. Anal. Chem., 66, 117 (1975).

10. M.S.Masoud and M.M.El-Essawi , Z. Phys. Chemie, 263, 1045 (1982).

11. S.Hedewy, S.K.Hoffman, M.S.Masoud and J.Goslar, Spectr. Lett., 19, 917 (1986).

12. M.S.Masoud, M.M.El-Essawi and A.M.Amr. Synth. React. Inorg. and MetOrg. Chem. 20, 839 (1990).

13. M.S.Masoud, A.M.Haffz and A.E.Ali, Spectr. Lett. 31, 901 (1998).

14. M.S.Masoud, I.M. Abed, A.E.Ali, J.Coord. Chem. 55, 153 (2002).

15. G.Schwartzenbach, "Complexometric Titration" Methuen Co., UK. London (1967), see also , A.I.Vogel, a Text book of quantitative Inorganic analysis, fourth Edition, p.116 (1978).

16. M. Rao Rama, D.Roy, J.K.D. Verma, J.Matter. Sci, 23, 2995 (1988).

17. R.M. Hill and A.K. Jonsher, Contemp. Phys. 24, 75 (1983).

18. A.K.Jonscher, "Dielectric Relaxation in Solid", Chelsea Dielectric Press Ltd., London (1983).

19. B.K. Chaudhuri, K. Chaudhuri and K.K. Som, J. Phys. Chem. Solids 50, 1137 (1989).

20. K.S. Cole and R.H. Cole J.Chem. Phys. 9, 341 (1941).

21. F.A.Grant, J. Appl. Phys. 29, 176 (1957).

22. P.B. Macedo, C.T. Moynihan and R. Bose, J. Chem. Glasses 13, 171 (1972).

23. K.K.Som, S.Mollah, K.Bose and B.K. Chaudhuri, Phys. Rev. B 47, 534 (1993).

24. J.T.S. Irvine, D.C.Sinclair and A.R.west, Adv. Mater. 2, 132 (1990).

25. I.M. Hodge, M.D. Ingram and A.R. West, J. Electroanal. Chem. 74, 125 (1976).

26. W.CAO and R. Gerhardt, Solid State Ionics 42, 213 (1990).

27. R.M. Hill and L.A. Dissado, J. Phys. C: Solid State Phys. 17, 6001 (1984). 